\title{
Early or Forced Marriage and the Roles of Primary Healthcare
}

\author{
Emmanuel A Agege ${ }^{1 *}$, Ezekiel U Nwose ${ }^{1,2}$, Samuel D Nwajei ${ }^{1}$, Joseph O Odoko ${ }^{1,3}, J^{\prime h n}$ E Moyegbone $^{1}$ and Eunice O Igumbor $^{1}$ \\ ${ }^{1}$ Department of Public and community Health, Novena University Ogume, Nigeria. \\ ${ }^{2}$ School of Community Health, Charles Stuart University, New South Wales, Australia. \\ ${ }^{3}$ Bayelsa State College of Health Technology, Otuogidi, Nigeria.
}

*Corresponding Author: Agege E. A. Department of Public and community Health, Novena University Ogume, Nigeria, Tel: +2347034330464 .

Received date: August 13, 2020: Accepted date: August 27, 2020: Published date: September 09, 2020

Citation: Agege E. A, Nwose E. U., Nwajei S. D, Odoko J.O., Moyegbone J.E. and Igumbor E.O., (2020) Early or Forced Marriage and the Roles of Primary Healthcare J, Clinical Medical Reviews and Reports. 2(6); DOI:10.31579/2690-8794/036

Copyright: (c) 2020, Agege E. A: This is an open access article distributed under the Creative Commons Attribution License, which permits unrestricted use, distribution, and reproduction in any medium, provided the original work is properly cited.

\section{Abstract}

Early marriage is the marriage done before or during adolescence, about $60 \%$ to $70 \%$ girls are forced to married early ages in several African and Asian countries. Even their basic human rights are not provided to them; these resulted several psychological and physiological health problems. The purpose of this paper is to narratively review the health problems/issues inherent in forced marriage and enunciate the roles of the public health care in ameliorating them. There was review of the health effects of early marriage grouped into psychological, pathophysiological, antenatal malaria and socio-cultural injustice, recommendations on how the public health-care roles can be useful tools to combating these unhealthy practices fostered by obsolete traditional beliefs and gross ignorance from both the victims and their parents. From the review of the previous studies, though no previous study has been documented in my locations for the study, there were great negative impactful health effects of early marriage on women, it was also obvious that the public health care providers can be vital in controlling or reducing these age-long anomalies. The grave dangers of early marriage on women were elucidated, its prevalence, the adverse consequences on the women as obviously observed were critically examined with enthusiasm and concerns. Therefore, the recommendations as per the roles of primary healthcare which includes teaching, surveillance, screening etc., in mitigating should be seriously adopted to curb the trend.

Keywords: early marriage, gender discrimination, public health care, parental ignorance, unexpected/early pregnancy

\section{Introduction}

According to the United Nations Human Rights Commission [1], early and/or forced marriage is a human rights violation, harmful practice and a form of sexual violence. There is strong belief that this social menace, which requires governmental and non-governmental stakeholders including corporate bodies to take steps to prevent or eliminate. The international legal framework applying to child, early and forced marriage has been detailed in earlier reports [2]. According to Mangeli, early marriage and motherhood is one of the most important health challenges in developing countries and affects mothers, children, families and communities, thus their causes and predisposing factors must be explored [3]. UNICEF also admitted that throughout the world, quite a good number of girls are suffering as a result of early marriage. Approximately $20-50 \%$ of girls are married by the age of 18 in developing countries and the ratio is higher in Sub Saharan Africa and South Asia and usually such girls are forced to marry with the man that are quite older than them [4].

It is expedient to note that age plays a vital role in the atmosphere of marriage. Experienced couples can reason though not in the exact way but reasonably acceptable ways that is consistent with marriage, but in early/forced marriage where the bride is grossly inexperience due to age, there will always be rancor because the parties will never be on the same page since their thinking will be at variance resulting in communication gaps and brutality from the husband of the woman in the marriage.

Early pregnancy resulting from child marriage have severe effect in the health of the girl. This was attested to by Taylor reported that about 16 million girls' ages 15 to 19 give birth each year in developing countries, complications during pregnancy and childbirth are the leading cause of death for girls in this age bracket. Children born to young mothers who are not physically or emotionally ready are at a higher risk of malnourishment and stunting. Many cultures and families see child marriage as a way to protect girls from premarital sex, sexual abuse and/or becoming pregnant out of wedlock (in the developing world, 90 percent of girls under 18 who gave birth do so in the context of marriage [5] However, the ill consequences of such action are not dully considered.

\section{The health problems}

It is an established fact that in uncivilized societies, evidences of getting married in early ages are greatly increased because of religious beliefs, norms and social impacts. There are health problems associated with early marriage and/or parenthood, which has been espoused in a previously published review. These health problems can be grouped into psychological, pathophysiological, malaria (ante and postnatal); and sociocultural injustice. The purpose of this piece of review, therefore, is to identify the public health problems inherent in early marriage, and how each of these broad categories could possibly be mitigated in primary health care. The health problems associated with early marriage are;

Psychological issue: For a marriage to thrive, the parties involved must be mentally matured and prepared, they must also be psychologically nurtured and educated. Unfortunately, the children who are victim of forced early or marriage barely knows anything about marriage and the intricacies adherent in it before they are forced into the 
adventure meant for only the fully grown. So, the victims are easily traumatized when the stresses involved in marriage start manifesting. Experienced couples can reason though in the exact way but reasonably acceptable ways that is consistent with marriage, but in early forced or marriage where the bride is grossly inexperience attributed to age, there will always be rancor because the parties will never be on the same page since their thinking will be a variance. This could result in communication gaps and brutality from the husband of the woman in the marriage.

Ahmed et al stated that due to ages involved in early marriages, young girls do not have the ability to deal with responsibilities of early pregnancy and pregnancy-related mortality and morbidity. This causes major physiological and psychological health issues in adolescent girls, resulting in losing relationship, confidence and ability to maintain a healthy relationship. Early marriage, multiple responsibilities and early pregnancies are risk factors of depression and it is further evaluated that married girls are at higher level when compared with unmarried [6]. Agege et al, from his previous work stated that mental illness is common among child brides due to their experience of domestic violence, girls who marry young are also more likely to think that wife beating is justified than women who marry later in life and parents or the significant others to these women do not see beating of wives are issues to be addressed, so to them it is normal in marriage for wives to be beaten by their husbands
[7]. According to UN, complications from pregnancy and childbirth are the leading causes of death for girls aged 15-19 years in developing countries. Out of the 16 million adolescent girls who give birth every year, about $90 \%$ are already married. UNICEF estimates some 50000 death, of which almost all are in low- and middle-income countries. Still births and newborn deaths are 50\% higher among mothers under 20 than in women who get pregnant in their late 20s [8]. Child marriage is often associated with developing countries where prevalence rates of $40 \%$ to $50 \%$ are not uncommon and child brides may face life-threatening health issues such as serious obstetric complications, including fistula and mental exhaustion because the systems involved are not physiologically developed. But marriage of adolescent girls also remains a persistent issue in the United States and other industrialized countries. Nour stated that more than half $(53 \%)$ of the women who married before the age of 18 years were reported to have had mental disorder such as depression compared with $49 \%$ of the women who married later. Former child brides also were substantially more likely to have a current mental health disorder (about $36 \%$ vs nearly $28 \%$ ) such as specific phobias. Nicotine dependence was also associated with child marriage. Mental health effects persisted even when the scientists adjusted for socio-demographic variables and the number of children a woman had. Additionally, former young brides were more likely to seek mental health care [9].

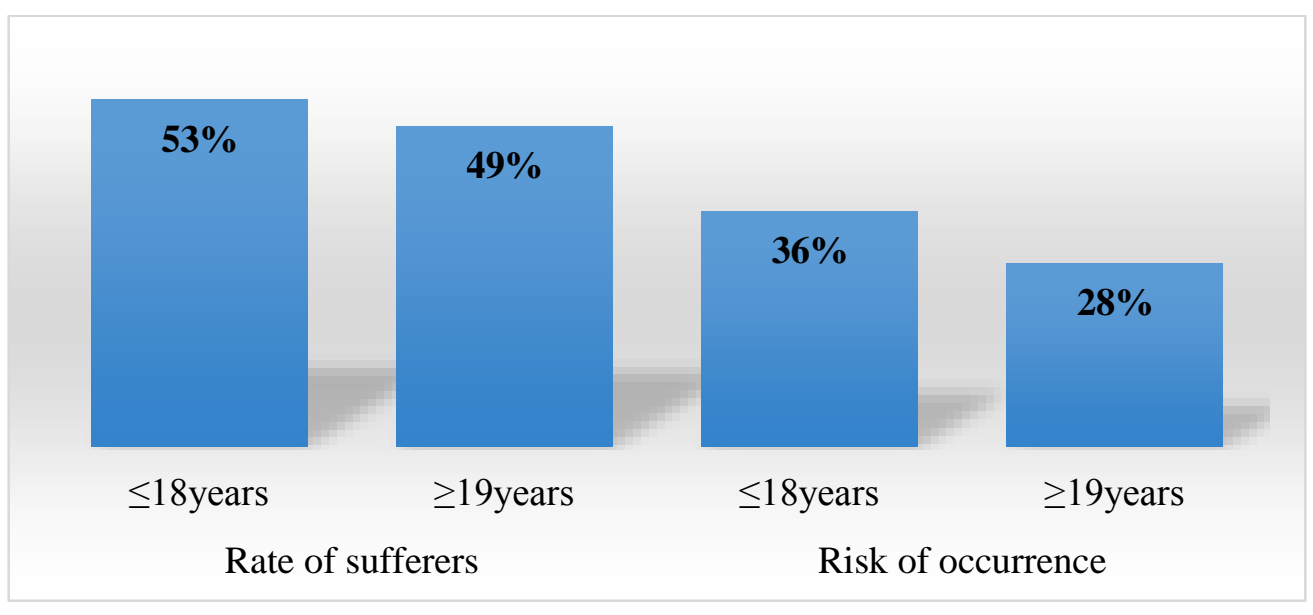

Figure 1: Report about mental health among child-brides

According to UNICEF, early marriage is the marriage done before or during adolescence, about $60 \%$ to $70 \%$ girls are forced to married in early ages in several African and Asian countries. Even their basic human rights are not provided to them; resulting in several psychological and physiological problems culminating in divorce or suicide. It is noted that the impacts of early marriages are very severe and disastrous for girls. Child marriage have many negative effects on girls' health such as increased risk for sexually transmitted diseases, cervical cancer, malaria, death during childbirth, and obstetric fistulas. They are also at increased risk for premature birth and death as neonates, infants, or children [10].

Public Health issue: The Psychological public health issues associated with early or forced marriage are mental disorders such as anxiety, depression, withdrawal, phobias, substances abuse, addiction, dependence, smoking, rages and violence. The above constitute health nuisance to the public life that could result to physical harms or injuries and at the extreme outright madness, and it becomes a public health burden to both the immediate family, friends, the health team and the public at large.
Patho-physiological issues: For a thriving marriage, there must be the physical maturity from the man and woman in it. Marriage comes with the demand for sexual indulgence, domestic activities, child-bearing and other issues that need physical involvement. The fact that the woman entangled in an early/forced marriage when not physically immature, the above activities would be too much burden for her to bear, and if they are not properly managed will result in severe health consequences. This led to Akanksha et al reporting that some of the negative health consequences of early marriage, for both mothers and their children, are related to the fact these women are so young. They are more likely to be having their first births and these are always riskier. Others are related to their physiology, for example, pregnancy complications associated with young age secondary to biologically immature mothers. They also opined that under-age marriage is a marker of multiple vulnerabilities, all of which reflect women's continuing low status in society, relative to men [11].

Child brides are more likely to become pregnant before their bodies are mature, increasing the risks of both maternal and newborn death and morbidity. Child marriage driven by poverty has many negative effects 
on girls' health, and these include increased risk for sexually transmitted diseases, cervical cancer, malaria, death during childbirth, and obstetric fistulas [12]. Study done in Uganda noted that the age difference between the men and their wives was a significant HIV risk factor for the wives, and age comparison of HIV prevalence between married and single women is shown in figure 2 [13].

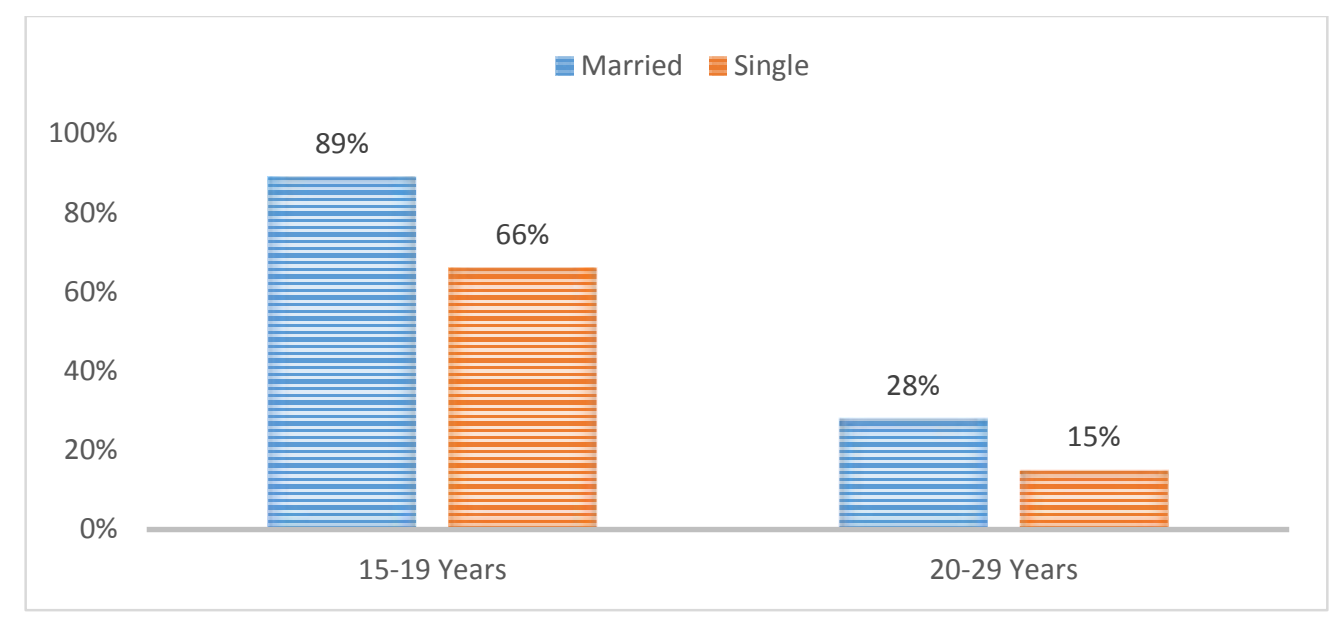

Figure 2: HIV prevalence reported among girls <30years

According to the WHO, UNICEF and UNFPA report, Nigeria and India had the highest estimated numbers of maternal deaths, accounting for approximately one third $(35 \%)$ of estimated global maternal deaths in 2017 , with approximately 67,000 and 35,000 maternal deaths $(23 \%$ and $12 \%$ of global maternal deaths), respectively. Three other countries also had 10,000 maternal deaths or more: The Democratic Republic of the Congo (16,000), Ethiopia (14,000) and the United Republic of Tanzania $(11,000)$. Sixty-one countries were estimated to have had just 10 or fewer maternal deaths in 2017 [12].

\begin{tabular}{|l|l|l|}
\hline Countries & Number of Maternal Death & Percentage of Maternal Death \\
\hline Nigeria & 67,000 & $23 \%$ \\
\hline India & 35,000 & $12 \%$ \\
\hline Democratic Republic of the Congo & 16,000 & $5.5 \%$ \\
\hline Ethiopia & 14,000 & $4.8 \%$ \\
\hline United Republic of Tanzania & 11,000 & $3.8 \%$ \\
\hline
\end{tabular}

Table 1: Estimated numbers and percentage of maternal deaths in Africa and Asia

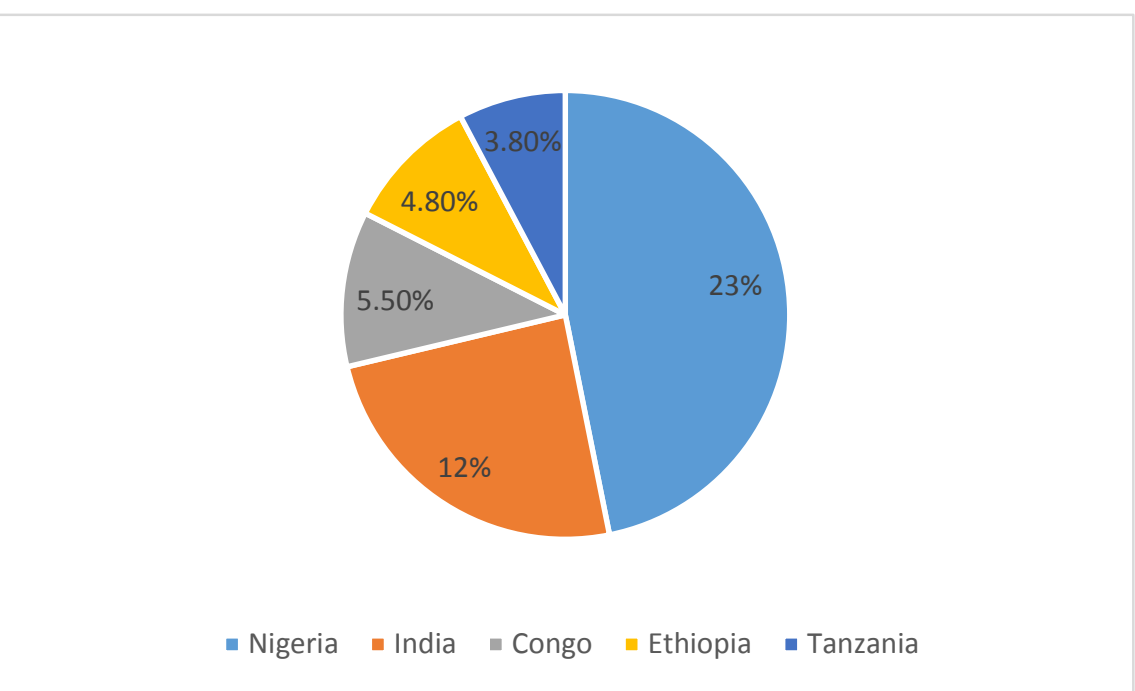

Figure.3: Percentage of maternal deaths in Africa and Asia

According to Steketee et al, the interaction between HIV and malaria in young married girls is devastating. Rates of co-infection are highest in Central African Republic, Malawi, Mozambique, Zambia, and Zimbabwe, where $>90 \%$ of the population are exposed to malaria and
$>10 \%$ are HIV positive. HIV-infected patients are much more susceptible to infection with Plasmodium falciparum. Pregnant women have high malaria parasitemia in the placenta and more severe clinical disease, which affects not just the first pregnancy but all subsequent pregnancies. 
HIV-infected patients also do not respond as well to standard anti-malaria treatment. Malaria infection in pregnancy have been responsible for anemia in pregnancy, and HIV infection in pregnancy confers additional risk for higher frequency and higher density of malaria during pregnancy [14].

Public Health issues with Patho-physiological problems: Those marrying early may be more susceptible to diseases like malaria and HIV, increased vulnerability to other sexually transmitted diseases, other issues like anemia, malnutrition, unwanted pregnancies, sexual and reproductive health morbidities and maternal mortality. The interaction between anemia, HIV and malaria in young married girls is devastating on their children and the victims themselves. The public health should aim at preventing these negative effects since prevention is one of their core duties.

Antenatal Malaria Issues: Malaria is one of the issues associated with African continent dwellers whether foreigners or indigenous. The WHO said that Malaria infection during pregnancy is a significant public health problem with substantial risks for the pregnant woman, her fetus, and the newborn child. Malaria-associated maternal illness and low birth weight is mostly the result of Plasmodium falciparum infection and occurs predominantly in Africa and that the symptoms and complications of malaria in pregnancy vary according to malaria transmission intensity in the given geographical area, and the individual's level of acquired immunity [15].

A study by Christine Luxemburger et al, posited that Falciparum malaria during pregnancy has long been recognized as an important determinant of low birth weight, the reduction in birth weight is usually more marked in primi-gravidae but can extend to second and third gravidae in areas of low malaria transmission. In malarious areas, malaria and anemia are likely to act together to reduce birth weight and premature birth resulting commonly from symptomatic malaria and is usual in severe malaria. Malaria during pregnancy leads to reduction in birth weight, and low birth weight is a major determinant of infant mortality. However, the major adverse effect of malaria in pregnancy on the mother is anemia [16]. It has been reported that Malaria is ranked third on major disease burdens in Malawi with an estimated four million cases occurring annually, mostly in pregnant women and children under 5 years old [17].

Alphonse Ouédraogo also reported that malaria infection during pregnancy poses a substantial risk to the mother, her fetus, and the neonate. In areas of stable malaria transmission such as Burkina Faso, where adult women have considerable acquired immunity, Plasmodium falciparum infection during pregnancy does not cause symptomatic malaria, but may lead to maternal anemia as well as placental and cord blood malaria infection, especially among primigravidae and secundigravida [18].

Julianna Schantz-Dunn and Nour Nawal agreed that malaria is a disease of poverty caused by poverty. They also opined that pregnant women infected with malaria usually have more severe symptoms and outcomes, with higher rates of miscarriage, intrauterine demise, premature delivery, low-birth-weight neonates, and neonatal death. They are also at a higher risk for severe anemia and maternal death. The study highlighted that Malaria has become one of the most challenging infectious diseases to eradicate in Africa. That the overall disease burden is devastating youth, women, and health systems. It not only debilitates the workforce, but keeps children from going to school, prevents pregnant mothers from effectively caring for their families, and decreases the likelihood of a healthy pregnancy outcome [19].

The above effects of malaria on pregnancy will be much more devastating on women who are victims of forced early marriage who have no source of livelihood but depend mainly on their husbands. An optimal health is a good antidote to malaria infection. So, a pregnant woman who have no enough funds for a healthy upkeep will easily succumb to the effects of malaria when pregnant because the poor feeding and lack of proper antenatal care will compound her status and ability to cope.

Studies have shown that the major adverse effect of malaria in pregnancy on the mother is anemia. It is reported that in malarious areas, malaria and anemia are likely to act together to reduce birth weight. It also reported that a study conducted in a highly malarious area of Papua New Guinea, severe maternal anemia worsens effects of malaria in pregnancy resulting in low-birth weight in primigravidae [20].

The above could be made worse judging from the report from a study carried by Agege which stated that more than half of the girls that were forced into marriage were forced into living with husbands without sources of income to adequately provide for their wives and this invariably mean that children being raised, that is if the women fortunately survive the poor antenatal period, will not be adequately catered for, so it is expected that anemia will be one of the problems that are associated with early marriage and pregnancy due to poor diet and lack of adequate knowledge on dietary requirements during pregnancy [7].

Unfortunately, Smith stated that the rate of death of the married girls aged between 15-19years is twice as compare to the girls who marry after the age of 20 years. As their bodies are immature that's why their health is affected by giving birth to a child [21]. While the WHO, UNDPA reported that the most important component of mortality for girls aged 15-19 are maternal deaths related to pregnancy and childbirth which accounts to 70,000 deaths per year worldwide due to malaria [12]

Public health issues with Antenatal malaria: The above effects of malaria on pregnancy will be much more devastating on women who are victims of forced early marriage who have no source of livelihood but depend mainly on their husbands. An optimal health is a good antidote to malaria infection. So, a pregnant woman who have no enough funds for a healthy upkeep will easily succumb to the effects of malaria when pregnant because the poor feeding and lack of proper antenatal care will compound her status and ability to cope. A study also reported that the high prevalence of anaemia observed in Kiboga district in Uganda can be attributed to poverty and limited access to nutrition and health education information which lead to low uptake and utilization of the public-health intervention package to combat anaemia in pregnancy [22].

Socio-cultural Injustice and Abuse: According to Plan International Canada, social justice means an array of important principles, like equality, peace, safety and freedom. Upholding social justice means valuing the rights of all individuals, and that unfortunately, the world isn't quite there yet. This has invariably led to millions of girls and women around the world to face social injustices, like being denied an education, forced into an early marriage, or made victims of genderbased violence. These injustices prevent girls and women from reaching their full potential [23]. It is a common traditional belief amongst the Southerners in Nigeria to accuse a woman of infidelity if her process of delivery is complicated or is prolonged beyond the expected delivery period and also when she did not deliver of the expected sex of a child. Here are two exemplary scenarios.

\section{Case Scenarios}

Scenario 1: There was a situation in one of the villages in the Niger Delta of Nigeria, where some soothsayers were met to consult the gods if the woman had been involved in sexual relationship outside her matrimonial home because she was undergoing a prolonged labor. At a point, the woman was made to confess and threatened that she will die if she did not comply with the tradition. This situation is worse if the woman 
had a stillbirth. This is due to abysmal ignorance from the people about fact that the married adolescence may have developed some complications because her birth canal has not been fully developed for the process of childbearing or the baby was too big for the delivery to occur naturally. There is also an instance of which, due to exhaustion during delivery, the baby died, and the woman was accused of being involved in abominable act resulting in the demise of the baby at birth. In a situation where the woman died during delivery and the child survives, the child lives with the stigma that the mother died while giving birth because the child was a bad omen.

Scenario 2: There was a case of abandonment of the mother and child in the hospital after delivery due to lack of funds to settle the hospital bills and her 'failure' to deliver of the expected sex of child - male child. Though abandonment was the final outcome, before the final abandonment, there were heaps of insults from the husband's relatives because the husband was the only male child and the family were relying on the wife to raise male children for the family. This led to refusal of food to her while still on the hospital bed, scolding on her by family members who visited her at the hospital. This woman was subjected to lots of emotional trauma and psychological harshness. Finally, she was abandoned along with her child without hospital bill paid.

The United Nations at the Fourth World Conference on Women, Beijing, 1995, stated that 'Sexual and gender-based violence, including physical and psychological abuse, trafficking in women and girls, and other forms of abuse and sexual exploitation place girls and women at high risk of physical and mental trauma, disease and unwanted pregnancy and that such situations often deter women from using health and other services' '[24].

Child marriage is recognized as one of the social malaises that needed to be addressed in order to achieve the above agenda of the United Nations.

The consequences of early marriage include early childbearing resulting to having too many children, main reason for school drop-out and less education. Those marrying early may be more susceptible to domestic violence, poor mental health, and malnutrition and they are also more likely to have limited access to contraception and healthcare. These negative effects may then impact their children, with daughters potentially also marrying young [7].
A story of child marriage in Northern Nigeria, Wasilla who was given out in marriage at the age of 14 years old, death was involved, and murder was suspected. If there is a public or sexual health impact of child marriage, death is the worst culmination of ill-health and this was a typical example. In the story of 10 years girl given out to marriage before being informed, suicide was attempted, and post-traumatic stress disorder was a complication [24].

Public Health issues with Socio-cultural Injustice and Abuse: There abound cases of abandonment of the mother and child in the hospital after delivery either due to lack of funds to settle the hospital bills or 'failure' of the woman to deliver of the expected sex of child. Though abandonment is the outcome, there is most often the underlying social determinants of health including the complex confounding factors of teenage pregnancy [25], as well as legalities of early marriage [24]. Pertinent amongst these factors is the impacts of neighborhoods on health behaviors, which entails socio-cultural injustices. For instance, being unmarried with unintended pregnancy could make the girl a subject of rejection in the family and stigma among peers [26].

\section{The roles of Primary Healthcare}

To recap the prevalence of adolescent pregnancy (Figure 4), recent fact sheet indicates early pregnancy remains a global issue [26]. In the views of adolescents, barriers to prevention of teenage pregnancy include lack of capacity and knowledge regarding methods as well as opportunity i.e. barriers in accessing "health services for the prevention of pregnancy" [27]. This epitomizes the need to advance the roles of PHC, especially for health education and promotion. Besides lack of awareness of health effects being attributable to causes of early marriage, the consequences of early parenthood are known to include issues of health care service affordances and other effects which could be advocated for and ameliorated at the primary healthcare facilities [26]. The idea to provide a program of pregnancy prevention services had been described long time ago. Such program is meant to comprise medical and social assistance in an adolescent-centered environment [28].

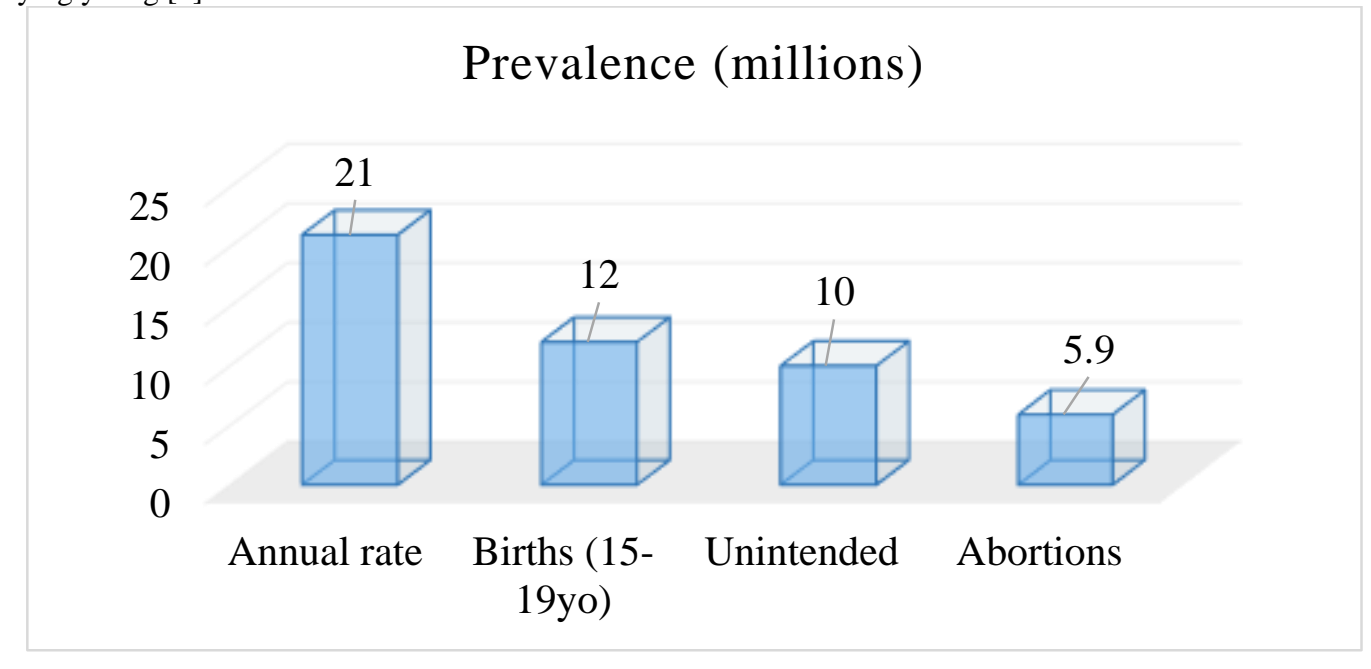

Figure 4: Adolescent pregnancy fact sheet as at 2020 [26]

Health Education: There may be controversies regarding the content of sex education program, but no gainsaying that health education is necessary [29]. For psychological issues, the public health personnel should do a lot of informative work via education or health awareness lectures on dealing with mental hazards associated with marriage on the victims of early marriage who is experiencing psychological effects or burden of early marriage. The public health team should be able to screen for early indications of psychological deviations such as excessive rage, 
nagging, withdrawal from friends and spouse, unnecessary crying and self- imposed starvation so as to nip them at the bud to forestall outburst that could snowball into devastating effects such as physical harm or death. If the victim is already visiting the health center, there could be more or frequent home visits for a proper follow up and the significant others to the victims should be coopted into the management of the victim. The health care team should educate the family members or the friends of the sufferers on the need to keep harmful things away from the victim because they are prone to suicide. Apart from preventing health consequences, a systematic review has reported up to " $30 \%$ decrease in adolescent births due to intervention by Community Health Workers [30].

Advocacy: Physiologically, the public health personnel should be at the Fore front advocating against early child or forced marriage emphasizing on the fact that if child is not allowed to be fully matured before going into marriage, there are graves consequences such as VVF, mortality/morbidity, malaria, etc. They can do this through jingles, visiting the community heads, regular awareness health lectures at the health centers. HIV and its associated risks has been identified as problems of early marriage being that the victims of early or forced marriage may not have adequate knowledge about preventive measures such as abstinence from sex with infected spouses, use of condom and screening or they may not be allowed by culture to abstain from sexual demand from their spouses, use condom while in marriage or the preventive tool like condom are not readily available. Anemia and malaria have been identified also as health issues in early or forced marriage. These are due to a lot of reasons ranging from poor or inadequate knowledge about good nutrition and poor or outright no usage of treated mosquito treated nets. The low economic status of the victims making her to be depending on the husband for proper upkeep which invariably will lead to poor feeding. Therefore, these are health issues that need the attention of the public health team. These can be addressed through enlightenment on good nutrition which can be sourced from within the locality of the victim. There should be education on the reason for the proper usage of the treated mosquito nets by all especially, the pregnant women. The public health should help the victim secure the net from the appropriate quarters at subsidized rate or in form of donations from the government. Suffice to note that the world's peak body on health advocates for enhanced advocacy [26]. Indeed, it is acknowledged that most dramatic outcomes in preventing early marriage vis-à-vis adolescent pregnancy is by advocacy-driven interventions including to develop and treat the young people as resources $[29,31]$. Yet, it requires a communitywide approach and training [32].

\section{Conclusion}

The health burden of early forced or marriage is better imagined than experienced it. It affects both the victims of such marriage, the families, friends and the society. It has both socio-cultural, economic, religious and political aftermaths. On the premise of ignorance from the parents of the victims, the public health team also need to articulate a program to enlighten them against forcing their daughters into early marriage with facts on how to prevent the health consequences of early marriage. The chance of dying of the infant of girl married before 18 years is 60 percent than that of the infant of the mother older than 19 years. If the child even survives, there are more chances of the fact that it will have low birth weight or is weaker than the normal children in physiological and psychological manners. This is the reason why all hands need to be on deck to cage the tetra headed ill-effects of these dastards acts of early or forced marriage by whoever has hitherto aided it directly or remotely because it is man's inhumanity to man. Finally, the public health team should be able to effectively work with communities and community leaders to understand the risks of child marriage and strengthening economic opportunities for vulnerable households, to create supportive legal and policy environment and supportive legal and policy environment that will enhance education, health, and protection for boys' and girls' against violation of their human rights and abuses.

\section{Acknowledgement}

Prof. Adjene J. A and all the members of the Public and Community Health Department, Novena University, Ogume are both appreciated for their support in this ongoing work.

\section{Funding: No funding sources}

\section{Conflict of interest: None declared Ethical approval}

\section{References}

1. United Nations Human Rights Office of the High Commissioner (2019). Child, early and forced marriage, including in humanitarian settings - Report of the United Nations High Commissioner for Human Rights (A/HRC/41/19) [EN/AR/RU].

2. Mangeli, M., Rayyani, M., and Cheraghi, M.A. (2017). Factors that encourage early marriage and motherhood from the perspective of Iranian adolescent mothers: A qualitative study. World Family Medicine. 15, 67-74. DOI: 10.5742/MEWFM.2017.93058.

3. United Nations Children's Funds. (2012). The State of the world's children.

4. Taylor K. (2019). Child marriage: Facts from around the world.

5. Ahmed, S., Khan, S., Alia, M., \& Noushad, S. (2013). Psychological impact evaluation of early marriages. International Journal of Endorsing Health Science Research (IJEHSR). 1, 84 - 86.

6. Agege, E. A., Nwose, E. U., and Odjimogho, S. (2018). Parental perception of girl-child early marriage amongst the Urhobos in Nigeria. Int J Community Med Public Health, 5, 3185-3190.

7. World Health Organization (2013). Child marriages: 39000 every day.

8. Nawal N. M (2009). Child marriage: A silent health and human rights issue. Rev Obs. Gynecol. 2, 51-56.

9. UNICEF (2015). Child marriage, adolescent pregnancy and family formation in West and Central Africa.

10. Marphatia A.A., Ambale G.S., and Reid A. M. (2017). Women's marriage age matters for public health: A review of the broader health and social implications in South Asia. Front Public Health 5, 269.

11. World Health Organization (2019). Maternal mortality: Levels and trends 2000 to 2017.

12. Kelly, R. J., Gray, R. H., Sewankambo, N. K., Serwadda, D., Wabwire-Mangen, F., Lutalo, T., \& Wawer, M. J. (2003). Age differences in sexual partners and risk of HIV-1 infection in rural Uganda. J Acquir Immune Defic Syndr. 32, 446-451.

13. Steketee RW, Nahlen BL, Parise ME and Mendendez C.. (2001). The burden of malaria in pregnancy in malaria-endemic areas. Am J Trop Med Hyg. 64, 28 - 35.

14. World Health Organization. (2017). Malaria in pregnant women.

15. Luxemburger C., McGready C, Kham A., Morison L., Cho T., Tan Chongsuphajaisiddhi T., Nicholas J. and White, F.N. (2001). Effects of malaria during pregnancy on infant mortality in an area of low malaria transmission. Am J Epidemiol. 154, 459-465.

16. Mwendera, C. A., de Jager, C., Longwe, H., Hongoro, C., Mutero, C. M., \& Phiri, K. S. (2017). Malaria research in Malawi from 1984 to 2016: a literature review and bibliometric analysis. Malar J, 16, 246.

17. Ouédraogo, A., Tiono, A. B., Diarra, A., Bougouma, E. C., Nébié, I., Konaté, A. T., \& Sirima, S. B. (2012). Transplacental transmission of plasmodium falciparum in a highly malaria endemic area of Burkina Faso. J Trop Med, 2012, 109705.

18. Schantz-Dunn J. and Nour N.M. (2009). Malaria and pregnancy: A global health perspective. Rev Obstet Gynecol. 2, 186-192. 
19. Brabin, B. J., Ginny, M., Sapau, J., Galme, K., \& Paino, J. (1990). Consequences of maternal anaemia on outcome of pregnancy in a malaria endemic area in Papua New Guinea. Ann Trop Med Parasitol, 84, 11-24.

20. Smith, G. C., \& Pell, J. P. (2001). Teenage pregnancy and risk of adverse perinatal outcomes associated with first and second births: population based retrospective cohort study. BMJ, 323, 476.

21. Mbule M.A, Byaruhanga Y.B, Kabahenda M. and Lubowa A. (2013). Determinants of anaemia among pregnant women in rural Uganda. Rural Remote Health. 13, 2259.

22. Plan International Canada. (2019). 3 Social injustices that girls face around world.

23. United Nations Chief Executive Board for Coordination (1995). Fourth World Conference on women.

24. Agege E.A., Nwose E.U., Odjimogho S., and Igumbor E.O. (2017). Legalities of child marriage in Nigeria: Implications on health and strategies of prevention. Sex Health Issues. 1, 1 - 4. DOI: 10.15761/SHI.1000105.

25. Short, S. E., \& Mollborn, S. (2015). Social determinants and health behaviors: Conceptual frames and empirical advances. Current opinion in psychology, $5,78-84$.
26. World Health Organization. (2020). Adolescent pregnancy.

27. Fiedler, M. W., Araújo, A., \& Souza, M. C. C. d. (2015). The prevention of teenage pregnancy in adolescent's view. Texto \& Contexto - Enfermagem, 24, 30-37.

28. Gordis, L., Fassett, J. D., Finkelstein, R., \& Tayback, M. (1968). Adolescent pregnancy: A hospital-based program for primary program. American journal of public health, 58, 849-858.

29. As-Sanie, S., Gantt, A., \& Rosenthal, M. S. (2004). Pregnancy prevention in adolescents. Am Fam Physician, 70, 1517-1524

30. Maravilla, J. C., Betts, K. S., Abajobir, A. A., Couto e Cruz, C., \& Alati, R. (2016). The role of Community Health Workers in preventing adolescent repeat pregnancies and births. Journal of Adolescent Health, 59, 378-390.

31. Realini, J. P. (2004). Teenage pregnancy prevention: what can we do? Am Fam Physician, 70, 1457-1458

32. Mueller, T., Tevendale, H. D., Fuller, T. R., House, L. D., Romero, L. M., Brittain, A., \& Varanasi, B. (2017). Teen pregnancy prevention: implementation of a multicomponent, community-wide approach. Journal of Adolescent Health, 60, S9-S17.

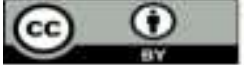

This work is licensed under Creative Commons Attribution 4.0 License

To Submit Your Article Click Here: Submit Article

DOI: $10.31579 / 2690-8794 / 036$
Ready to submit your research? Choose Auctores and benefit from:

* fast, convenient online submission

* rigorous peer review by experienced research in your field

* rapid publication on acceptance

* authors retain copyrights

* unique DOI for all articles

* immediate, unrestricted online access

At Auctores, research is always in progress.

Learn more www.auctoresonline.org/journals/clinical-medical-reviewsand-reports 